\title{
EXPRESIONES DE LA INTIMIDAD POLÍTICA DESDE EL CUERPO DE LAS MUJERES ACTIVISTAS
}

EXPRESSIONS OF PRIVACY POLICY FROM THE BODIES OF ACTIVIST WOMEN

GuitTÉ HaRToG*

Ana Lorena Carrillo Padilla

LOUISE REATHOUSE AMADOR

troisgatos@hotmail.com

\author{
Por: Guitté Hartog* \\ Ana Lorena Carrillo Padilla \\ Louise Greathouse Amador
}

Artículo Recibido: 6 marzo 2013. Artículo Aprobado: 1 mayo 2013.

\section{RESUMEN}

A partir del contexto contemporáneo mexicano se busca ilustrar cómo a través de su cuerpo algunas mujeres van protestando en contra de diversas formas de opresión. El exhibicionismo de la intimidad femenina se vuelve un estilo de empoderamiento para decir "NO" desde las entrañas al oscurantismo imperante y para gritar su deseo de vivir libre. A través del activismo tanto en el espacio virtual que en las plazas públicas analizaremos estos actos de rebeldía que unen lo íntimo a lo político.

Palabras claves: exhibicionismo, opresión, espacio virtual, intimidad política, mujeres activistas.

\section{ABSTRACT}

We seek to illustrate, from Mexican contemporary context, how some women use their bodies as a way to protest against various forms of oppression. The exhibitionism of female intimacy becomes a way of empowering to say "NO" to the prevailing obscurantism and to shout what their desire to live freely. Is through activism both in the virtual space and public places we will analyze these acts of rebellion that link the intimate space to the political actions.

Key Words: exhibitionism, oppression, virtual space, privacy policy, activist women.

Cuerpos luchando en un México ya no tan lindo Objeto de deseo, de codicia, de dominación, de miedo, el cuerpo de la mujer fue, a través de la historia, un espacio definido, reglamentado, ocupado, honrado o conquistado por la fuerza de los hombres.

Denise Bombardier

Artículo de Reflexión según clasificación de Colciencias.

Lo íntimo es político. 


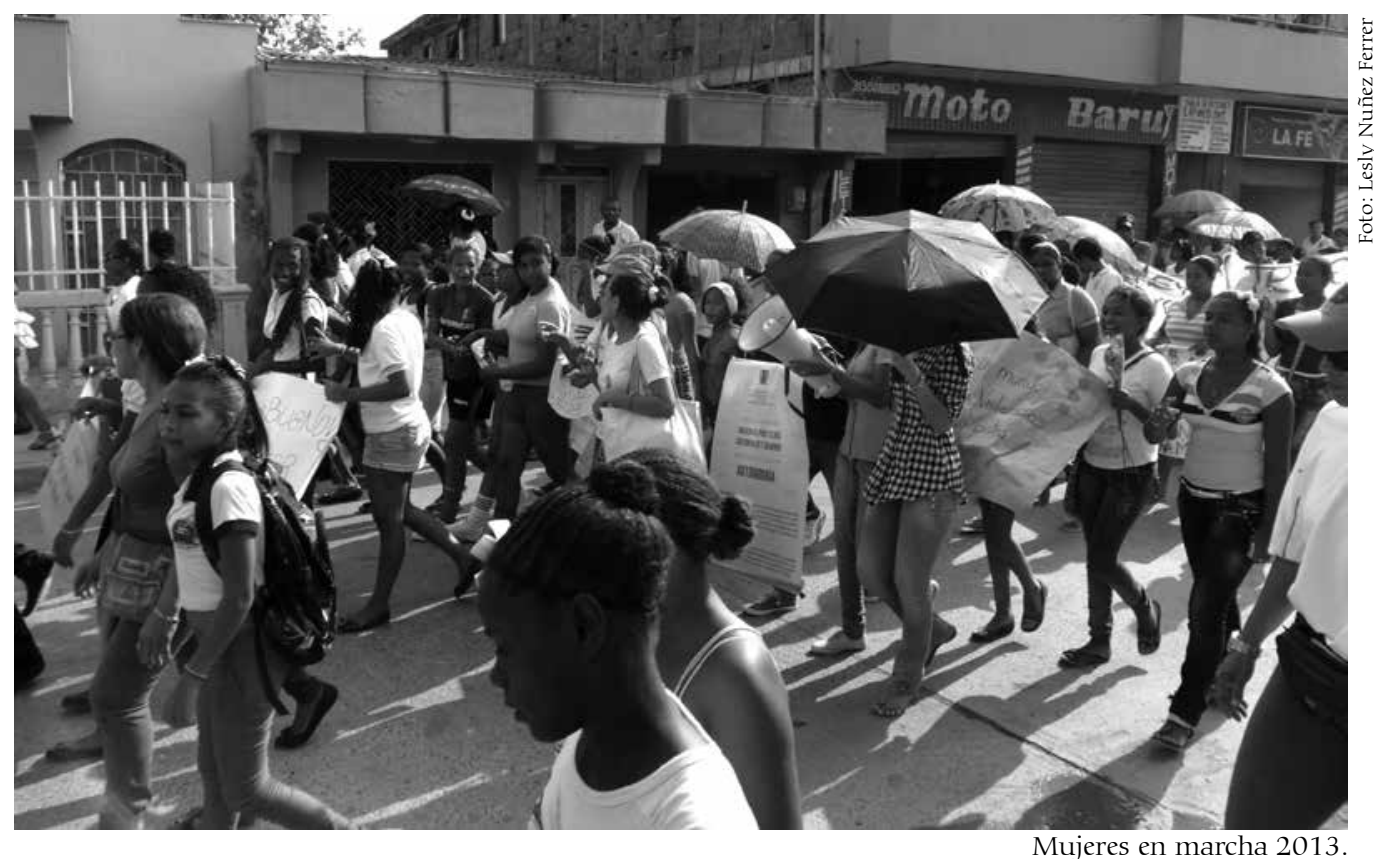

En este texto queremos explorar, a partir del contexto mexicano, cómo, desde su corporalidad, algunas mujeres mexicanas luchan de manera creativa en los espacios públicos para reivindicar pacíficamente sus derechos y visibilizar sus demandas. A partir de la observación participante a mas de 15 actos de protesta (como marchas, actos y performance) así como del activismo en las redes sociales (como Facebook) de mas de 200 amigas, grupos y páginas abiertamente feministas, intentaremos mostrar el carácter creativo y dinámico de estas manifestaciones que contrastan con el ambiente anticuado de una derecha sofocante y de una izquierda que no logra distinguirse para inspirar el sueño de que otros mundos son posibles. Denunciar los feminicidios, la desaparición forzada de mujeres, la trata de personas, la criminalización del aborto, la homofobia y defender el derecho de las mujeres a una vida libre de violencia y a vestirse con libertad sin ser agredidas son actos políticos que involucran aspectos de la corporalidad y de la sexualidad. Se presentarán los eslóganes, manifiestos y expresiones visuales que ilustran este proceso de empoderamiento.

Tradicionalmente, en el imaginario social México es reconocido por ser tierra de los machos verdaderos y de la abnegación femenina. Esta situación, paradójicamente fue propicia a las luchas feministas y uno de sus momentos clave fue en 1975 la celebración de la Primera Conferencia Internacional de las Naciones Unidas sobre las Mujeres en México. Entre avances y resacas los derechos de las mujeres se han visto corrompidos por discursos oficiales y leyes progresistas que poco se aplican en una sociedad que sabe mucho de derecha pero poco de derechos humanos. 
La sociedad mexicana es actualmente sumergida en una ola de violencia sin precedente en un contexto de guerra contra el narcotraficante, de militarización del país y de recrudecimiento de los fundamentalismos religiosos. En 2011, 27. 199 personas fueron asesinadas según un reporte publicado por el Instituto Nacional de la Estadística y Geografía (Inegi). En cinco años, el aumento de homicidio sube hasta los 306 \% (Le Monde, 23 septiembre 2012).

http://www.lemonde.fr/ameriques/article/2012/08/23/le-mexiquesubmerge-par-une-vague-de-violence_1749022_3222.html

Esta situación de profunda inseguridad tiene un impacto particular sobre las mujeres. En efecto esta legitimación de la violencia por parte del Estado para aniquilar los carteles de la droga fomenta la impunidad de los actos violentos y hace pasar fenómenos como los feminicidios de Juárez como secundarios. (Labrecque, 2012).

\section{EL CUERPO NO MIENTE... Y ENCARNA LAS LUCHAS}

En tiempos de oscurantismo... de inseguridad social y de retrocesos en las políticas públicas, tales como los que estamos viviendo en México, se hace necesario repensar los espacios de socialización, el mundo político y hasta la propia intimidad. Frente a la pérdida de credibilidad en las instituciones y en los ideales políticos, los cuerpos siguen la realidad más inmediata de las personas. La violencia, el miedo, la coerción, el placer, el hambre y el dolor se viven en carne propia.

La creatividad de las manifestaciones de las feministas mexicanas tiene un gran potencial de humanización que contrasta con una ciudadanía desilusionada. Fuera del mundo superficial del entretenimiento televiso, de la simulación de la preocupación por la equidad de género y del derecho de las mujeres a una vida libre de violencia por parte de una clase política corrupta, todavía existen mujeres reales, de carne y hueso, que están dispuestas, sin ser acarreadas, a luchar por una sociedad mejor. Por más marginales que sean estas manifestaciones, estas últimas abren brechas y proponen alternativas para salir de la alienación que nos proponen los gobiernos, el mundo del consumismo, la Iglesia y los mal llamados medios de comunicación. Además, aun cuando ciertos discursos pueden considerarse como radicales, hay que destacar el carácter muy pacifista de estas manifestaciones. Mientras el machismo viola, tortura y mata todos los días, el feminismo como movimiento social ha logrado, a lo largo de la historia, varios avances a favor de una mayor justicia social sin ninguna gota de sangre. 
Simbólicamente, y en el imaginario colectivo, la imagen corporal femenina ha llamado más la atención. Consideradas como el bello sexo o, literalmente, las personas de sexo agregado a su poder materno... las mujeres han sido vigiladas a través de su belleza, sexualidad y maternidad desde tiempos inmemoriales. El famoso refrán "Eva otra vez tiene la culpa" reitera cómo lo femenino fue y sigue asociado al pecado, a la pérdida de control y a la lujuria.

Comúnmente se dice que una persona da la cara para responder a una acusación o asumir una causa, pero parece que, en el caso de las mujeres, ellas tienen que dar el cuerpo entero. Mientras los hombres públicos andan por lo general en un traje convencional que tapa su cuerpo, las mujeres "públicas" parecen ser puestas en vitrina, expuestas a las miradas que las auscultan y que interpretan sus almas, sus estados de ánimo y su carácter según lo que perciben. Esta vigilancia social sobre el cuerpo femenino lo convierte en un territorio de lucha política. El largo del cabello, de las pestañas, de la falda, el grosor de los senos, de los labios, de la cintura... el tipo de vestimenta, los colores, el maquillaje... etcétera, todo en la apariencia de la mujer parece mandar un mensaje ideológico.

Cuando se habla de crear un mundo más justo, libre y digno para todos los humanos, tanto los hombres como las mujeres están presentes. Pero, las mujeres además se tienen que emancipar de la dominación masculina. Vale la pena subrayar que los hombres viven también bajo mandatos de género y que estos tienen diversos impactos negativos sobre su salud y sus expresiones corporales (De Keijzer, 2010). El contexto de machismo, homofobia y misoginia imperante afecta a toda la sociedad; no obstante, en este texto nos concentraremos en las reivindicaciones feministas que, por varias razones, se han vuelto más viscerales y visibles que en el caso de los hombres. Ya que, a pesar que los hombres viven bajo el espectro del patriarcado y pueden sufrir por ello, todavía no hemos asistido a grandes manifestaciones públicas de hombres en contra del machismo, por el derecho a decidir o en contra del hostigamiento sexual. Las marchas del orgullo gay a favor de la diversidad sexual serían la expresión más cercana de una oposición al sistema de género y a su estructura heterocéntrica.

En este sistema dicotómico, que describe Hannah Arendt (2003), lo masculino se diferencia de lo femenino y es superior a él. Al hombre se le asocia con lo racional, lo fuerte, lo público... mientras a la mujer con lo emocional, lo débil y lo privado. Tradicionalmente, las mujeres fueron consideradas 
las sombras naturales de los hombres y condenadas a vivir bajo su tutela, y eso en casi todos los ámbitos, sean estos familiares, religiosos, laborales o gubernamentales. Este sistema que llamamos patriarcado inculca varias reglas de convivencias entre los géneros y la principal es, probablemente, la de fomentar una vocación femenina de servidumbre hacia los hombres. Este servilismo justifica la imposición de un importante instructivo sobre el uso del cuerpo femenino. Otra aportación de este sistema ideológico es la separación de los aspectos racionales y corporales. Y, si cruzamos los conceptos, podemos constatar que con ello se naturaliza la idea de que los hombres deciden, legislan y piensan sobre el cuerpo de las mujeres. De allí, la gran resistencia a que las mujeres piensen, decidan y legislen sobre su propio cuerpo. Pensar que las mujeres son dueñas de su propio cuerpo, capaces de reivindicar su libertad y de aspirar a la justicia sobre la plaza pública amenaza con transgredir todo un orden social basado en la dominación masculina.

Calladita te ves más bonita.

Dicho popular

La mujer debe estar como la escopeta: siempre cargada y detrás de la puerta.

Dicho popular

Las mujeres son seres de cabello largo y de ideas cortas.

Pierre J. Proudhon

Marcela Lagarde (1997) ha expresado, explícitamente, cómo las mujeres parecemos tener un cuerpo para los otros y que, de cierta manera, vivimos en estado de cautiverio. Desde lo doméstico, lo sexual, lo económico, lo simbólico, etcétera, dependeríamos las mujeres de lo que piensan y quieren hacer los demás con nuestro cuerpo. Simone de Beauvoir (1949), cuando decía que lo biológico no tendría que ser destino, enunciaba de cierta manera que no por tener un cuerpo de mujer se tenía que vivir limitada o dependiendo de lo que dicta la sociedad sobre la feminidad y la masculinidad.

Judith Butler (2000 y 2001) retoma de manera contemporánea esta idea de destino hablando más bien de escenarios, guiones y personajes impuestos a partir de los genitales. Para ella, el género es esencialmente un performance; 
un papel actuado que es atribuido históricamente a partir del momento en que se identifican los órganos sexuales de un ser humano. No solamente a partir de allí se atribuyen el color y el estilo de la ropa, "el traje", sino también otros elementos como los accesorios, los juguetes y, aún de una manera más trascendental, las trayectorias de vida posibles. Como lo plantea Hannah Arendt, este sistema deja poco espacio para otras posibilidades inter o trans género más allá de la dicotomía hombre-mujer.

El concepto de performatividad, que proviene de las artes escénicas, se vuelve útil para entender la ruptura de paradigma que ocurre cuando las mujeres mexicanas buscan cambiar el escenario de su país involucrándose en una protesta social. Adueñarse de los espacios públicos para manifestar su derecho a ser dueña de su propio cuerpo. Estos cuerpos femeninos pensantes que reclaman a gritos libertad y dignidad transgreden no solamente todo un imaginario social sobre la feminidad sino que abren nuevos horizontes a las concepciones tradicionales de democracia... que empiezan a veces por la cama o un seno indignado. Una sociedad que no permite a las mujeres, la mitad de su población, ser libre con su cuerpo no es democrática. La paz y la seguridad social para las mujeres nunca será una realidad sin una profunda lucha contra el machismo y la violencia masculina.

De cierta manera, las activistas buscan ser actoras sociales y dejar de ser las simples actrices o títeres de un rol femenino social limitado que les es asignado en un escenario patriarcal. Hartas de ser objetos decorativos o fieles "madresposas" (expresión utilizada por Marcela Lagarde) abnegadas las mujeres se unen buscando hacer visibles sus deseos de emancipación e ir más allá de todo lo que se ha visto hasta ahora.

En las próximas líneas presentaremos algunas de las reivindicaciones feministas que a partir del cuerpo claman libertad, justicia y el derecho a gozar de una vida libre de violencia.

Ni Dios, ni Estado, ni partido, ni marido.

Este cuerpo es mío: no se toca, no se viola, no se mata.

Dueñas de nuestros cuerpos, dueñas de nuestras vidas.

Una aspiración de los movimientos feministas es el derecho de las mujeres a vivir libres y a ser dueñas de su propia vida. En este sentido el cuerpo juega un papel fundamental. Si las mujeres no deciden sobre su propio cuerpo 
difícilmente van poder decidir sobre otros asuntos. En el contexto de las relaciones internacionales se manejan asuntos de geopolítica como la soberanía de un país, la autonomía de un pueblo o de una institución, las violaciones territoriales... pero en el caso de las mujeres, su cuerpo se vuelve un territorio ocupado. El Estado, la religión, los grandes corporativos, el mundo de la moda y casi toda la sociedad entera encierran a las mujeres en estereotipos que las encadenan en papeles sofocantes.

Ni santas, ni putas, solamente mujeres...

Me quieren virgen, me quieren santa, ¿saben qué? A la chingada... No soy una vagina, no soy solo unos pechos, soy una mujer exigiendo sus derechos...

La doble moral hace que las mujeres, más que los hombres, tengan que luchar para gozar de su sexualidad sin prejuicio en una sociedad donde el puritanismo se mezcla con el morbo sin aparentes contradicciones. La dicotomía que divide a las mujeres entre santas y putas no pesa de la misma manera sobre los varones. Por ejemplo, no nos imaginamos a hombres con pancartas diciendo: "Ni santos, ni putos, solamente hombres..." o "Me quieren virgen, me quieren santo, ¿saben qué? A la chingada" o tal vez "No soy un pene, no soy unos testículos, soy un hombre exigiendo sus derechos...".

En este sentido "La marcha de las putas", que fue una iniciativa internacional iniciada en Toronto (Canadá) por la indignación que provocó, en abril de 2011, el policía Michael Sanguinetti quien explicó en un salón de clase de la Osgoode Hall Law School de Toronto que si las mujeres no querían ser violadas no tenían que andar vestidas de putas (Facebook, Marcha de las Putas, Ecuador).

Las numerosas y muy concurridas marchas alrededor del mundo y principalmente en México evidenciaron que no solamente el adjetivo "puta" es un estigma que violenta simbólicamente a las mujeres como grupo social sino que justifica que algunos hombres violen a las mujeres y hasta puedan matarlas por andar como "putas".

iAlerta, alerta, alerta que camina, "La marcha de las putas" por América Latina!

De una puta vez que quede claro: no es no.

Escucha, baboso, yo escojo a quien me cojo.

Las putas insistimos: los políticos no son nuestros hijos. 
No es no, fue la principal consigna de "La marcha de la putas". La sencillez del mensaje tenía como objetivo que todos los hombres, de los más sencillos a los más sofisticados, entendieran de una vez por todas que las mujeres tienen el derecho a decidir si quieren o no tener una relación sexual sin importar su vestimenta. Sin querer dar nombres, en el Estado de Puebla tuvimos, en 2011, dos declaraciones oficiales de altos funcionarios públicos que argumentaron la relación entre las mini-faldas, los escotes, las blusas y pantalones apretados y la violación de las mujeres. En lugar de cuestionar el machismo y de abogar por la libertad de las mujeres, pretendieron reducir el hostigamiento laboral y las agresiones sexuales a través del control más estricto de la vestimenta femenina.

El control patriarcal sobre el cuerpo de las mujeres no se edifica solamente sobre la sexualidad sino también sobre la maternidad. En México, desde que se despenalizó el aborto hasta las doce primeras semanas de gestación, en el resto del país soplaron vientos de derecha para impedir que las mujeres gozaran de los mismos derechos que en la capital. Se votaron iniciativas para proteger la vida desde la concepción hasta la muerte natural y se criminalizó con más intensidad a las mujeres sospechosas de haberse provocado un aborto.

\section{Saquen estos rosarios de mis ovarios.}

Educación para decidir, anticonceptivos para no abortar y aborto legal para no morir.

Si el Papa fuera mujer, el aborto sería legal.

El tema de la maternidad elegida que implica el derecho al aborto genera debates éticos importantes. Sin embargo, son las autoridades de la Iglesia católica, únicamente compuestas de hombres que en teoría practican el celibato, las que influyen en las políticas públicas en materia de derechos sexuales y reproductivos. En otras palabras, una minoría sexual se apodera de las cuestiones reproductivas ejerciendo su autoridad sobre el cuerpo de las mujeres, sin pensar que el proceso se desarrolla en su cuerpo y que la maternidad va mucho más allá del proceso biológico de reproducción.

En el caso de los feminicidios, de las desapariciones forzadas, de la trata de mujeres con fines de explotación sexual y del asesinato de mujeres activistas las manifestaciones son realizadas bajo un dolor y un miedo profundo. Pero cómo no reclamar la muerte de una de las nuestras, no expresar el dolor y reclamar justicia a las autoridades y pedir que haga algo para prevenir la desaparición de más mujeres. 
Ni una más.

A mí también me van a matar por exigir justicia.

Todas somos Maricela.

Susana Chávez vive.

En el Estado de México mi vida no vale nada. Alerta de género denegada.

Los asesinatos de Maricela Escobedo, quien exigía justicia por el asesinato de su hija Ruby, y de Susana Chávez, poeta a quien se le atribuye la famosa frase: "Ni una más", ha indignado profundamente al mundo de las activistas sociales. Susana Chávez fue encontrada con una mano cortada, la mano con la cual escribía y denunciaba el feminicidio en Ciudad Juárez. Como observan Liliana Paola Ovalle (2010) y Salvador Cruz Sierra (2011), los cadáveres encontrados en las plazas públicas también son mutilados, desnudados y colocados en posiciones sexuales para mandar mensajes. De cierta manera los cadáveres son utilizados para hacer un performance.

Frente a la violencia social generalizada en el país, las víctimas de los feminicidios y las feministas se unieron a la famosa campaña nacional "No más sangre" que lanzaron los caricaturistas y al "Movimiento por la Paz y la Justicia" que lanzó el poeta Javier Sicilia después del asesinato de su hijo. En el contingente de las marchas "Estamos hasta la madre" varios colectivos, como el de "Nuestras hijas de regreso a casa" se unieron a familias de crímenes impunes.

Los movimientos lésbico-gays están presentes en casi todas las manifestaciones. La bandera del arco-iris de la diversidad sexual acompaña casi todas las luchas sociales en favor de la libertad, de la justicia y la dignidad de las mujeres mexicanas.

\section{Una revolución en cada beso.}

No me gusta el PAN, me gusta la tortilla nacional.

Acostumbradas a luchar por ser reconocidas y por salir del armario, algunas mujeres lesbianas, bisexuales y trans desarrollan un fuerte sentido de compromiso social para sensibilizar a las autoridades y a la población en general respecto a la diversidad, a la convivencia pacífica y al derecho a amar y gozar libremente. Y, desde luego, estas aspiraciones implican la posibilidad de vivir sin ser asesinadas. 
Tomarse a pecho los problemas de su país

Desde Ucrania se hicieron muy famosas las integrantes de un grupo llamado FEMEN, de mujeres rubias muy sexys que se manifiestan con los senos desnudos contra la explotación sexual de las mujeres, el sexismo, las dictaduras, la pobreza y las diferentes formas de esclavitud. Su desnudez es asumida como un recurso para llamar la atención de los medios de comunicación y del público en general sobre las causas que creen importantes. Exhibir su belleza les permite usar el potencial erótico -el mismo que se usa para vender cerveza o dar prestigio a un evento político o deportivo- para publicitar un discurso emancipador.

La desnudez en lugares públicos constituye, todavía, una transgresión a lo que se considera el pudor, la decencia y las buenas costumbres. Las manifestaciones de hombres y mujeres indígenas y campesinos que se desnudaron en la capital de México o ciertas marchas feministas o la famosa quemada de sostenes de los años 70 en Estados Unidos no usan el poder de la belleza pero sí el de llamar la atención. En el caso específico de las personas indígenas en las capitales se trata, más bien, de salir de la invisibilidad, de gestos de desesperación por ser escuchados y tomados en cuenta después de largos y numerosos intentos para que sus demandas sean atendidas por las autoridades.

Exponer las zonas erógenas en público es una manera de enseñar la propia vulnerabilidad perturbando el orden social. Es permitir a los demás mirar la intimidad y, metafóricamente, mostrar su autenticidad y que no se tiene nada que esconder. Mostrarse sin armadura y sin ropa, paradójicamente, es una excelente manera de acabar detenido por la policía.

Los senos son considerados como parte de la sensibilidad femenina. En México, un grupo muy activo se denomina "La chichi indignada". Se define como una red de mujeres que están indignadas por la grave situación de violencia contra las mujeres en México. Como lo indica su página en Facebook:

Nuestro propósito es contribuir a visibilizar, documentar y denunciar los problemas y las heridas que nos duelen: el feminicidio, la trata de personas, los secuestros, asesinatos, desapariciones, agresiones y hostigamiento sexuales contra las mujeres. También nos preocupa evidenciar y denunciar la violencia estructural y sistemática que padecemos las mujeres de todos los 
ámbitos socioeconómicos y culturales y la falta de garantía de nuestros derechos humanos, aunadas las discriminaciones por razones de preferencia sexual, edad, discapacidad, etnia, lengua, clase, nivel de escolaridad, ideología y condiciones de salud.

Nuestro actuar es la movilización pública, virtual y física, de nuestras ideas, denuncias y demandas. Estén pendientes de nuestras campañas y acciones para que se sumen solidariamente y contribuyan donde quiera que estén.

\section{"Sin chichis no hay país"}

La chichi Indignada

\section{De pelos...}

No existe un único feminismo ni una única manera de manifestarse. Si ciertos grupos prefieren exacerbar su feminidad, otros optan por agregarse más virilidad. Aunque existen performances que combinan los senos desnudos y el atuendo viril. El colectivo "La Barba" en Francia y Las Bigotonas en Puebla, México, sacuden la dominación masculina y el machismo de las buenas conciencias utilizando barbas y bigotes y mucho humor. Los discursos cínicos que anhelan la virilidad leídos por mujeres barbudas y bigotonas tienen por objetivo despertar la inquietud en el público para reflexionar sobre el supuesto de que "todo anda bien" mientras las mujeres son minoría en el poder y sus aspiraciones no son escuchadas por no tener ciertas características masculinas. Se espera que una barba o un bigote produzcan una impresión de confusión de género voluntariamente no sexy que permite mostrarle al público la gravedad o seriedad del asunto; cualidades, estas últimas, que son consideradas el fuerte de los hombres. Pero, como en todas las manifestaciones -sexys o no sexys-, la audacia de transgredir las normas del buen gusto y del orden social establecido es utilizada para llamar la atención del público y mostrar los desacuerdos a partir del propio cuerpo.

Para que respeten mi útero... itendré que ponerme bigote?

Vírgenes bigotonas 


\section{EN CONCLUSIÓN}

Gioconda Belli (2011) en su novela "El país de las mujeres" presenta al PIE, el Partido de la Izquierda Erótica, compuesto de puras mujeres, como una alternativa a los sistemas políticos que se conocieron hasta ahora. Desde la utopía feminista y la ficción se hace una pregunta fundamental: ¿cómo sería un país dirigido por mujeres feministas? Sobre estas preocupaciones territoriales, Virgina Woolf, ya en 1929, presentaba un ensayo titulado "Un cuarto propio" que expresaba la necesidad de las

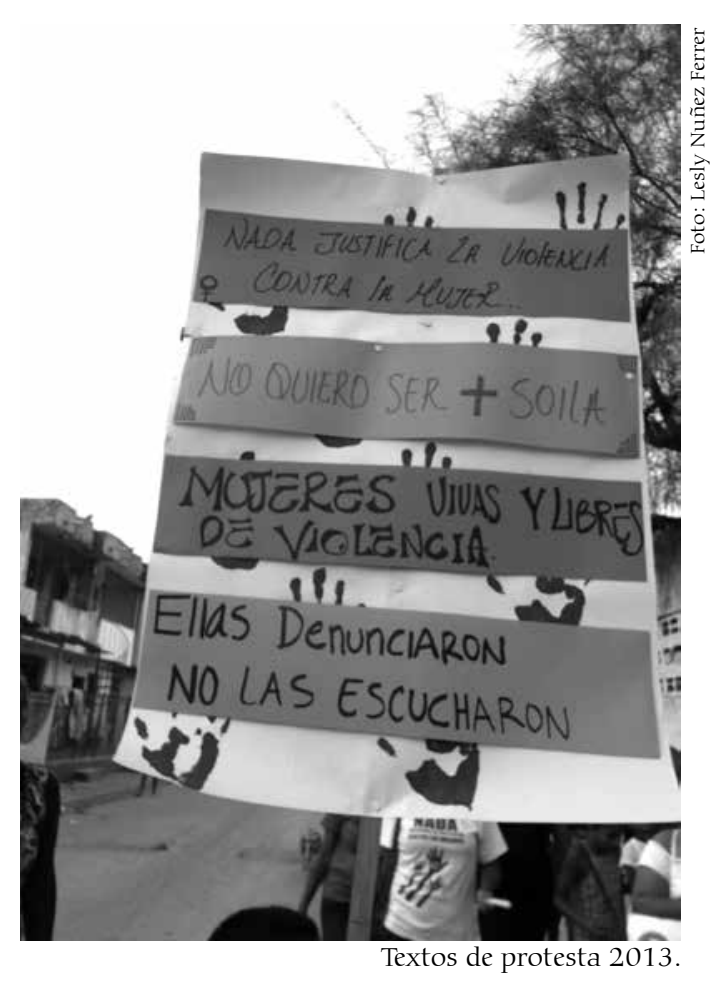
mujeres de tener un espacio suyo para poder escribir, pensar y existir. En las manifestaciones que hemos presentado en este texto se evidencia que muchas mujeres, lejos de tener un país o un cuarto propio, ni siquiera parecen haber logrado habitar un cuerpo, sobre el cual ellas manden.

Sin embargo, la capacidad de sentir la indignación desde el mismo cuerpo, sin expresarla de manera violenta sino más bien creativa y hasta erótica, plantea nuevas formas de ejercer el poder para exigir justicia, dignidad y libertad. El cuerpo femenino se vuelve político y un medio a través del cual se pueden exigir cambios en toda la sociedad. Podríamos hablar de vitalidad de la ciudadanía, de horizontes utópicos que no son desencarnados de las realidades cotidianas y profundas de las mujeres.

En este sentido, asistimos a una fusión de lo público con lo privado, de lo racional con lo emocional y de lo corporal con lo político. Lejos de las dicotomías que presentaba Hannah Arendt (2003) estaríamos hablando de transmodernidad. El ciberfeminismo es parte de esta transmodernidad donde lo muy íntimo y personal se vuelve público y, a veces, politizado. Como lo explica María del Carmen García Aguilar (2010), a través de las redes sociales que permite el internet asistimos a individualidades solidarias que pueden hacer su propio teatro en una plaza pública. Estos performances permiten salir de la clandestinidad e inconformarse públicamente con bastante libertad 
y tener un impacto global casi en tiempo real. Sin remplazar a la calle, el ciberespacio permite otra forma de manifestar la inconformidad, pero también de organizar las protestas y de ir construyendo las redes de apoyo.

\section{BIBLIOGRAFÍA}

Arendt, H. (2003), La condición humana. Paidós. 384 p. Espagne.

Belli, Gioconda (2010). El país de las mujeres. Ed. La otra orilla. Nicaragua.

Butler, Judith. (2000). "El marxismo y lo meramente cultural", en New Left Review N². MayoJunio, 2000. 109-121. http://www.cholonautas.edu.pe/modulo/upload/butl.pdf

Butler, J. (2001) El género en disputa, el feminismo y la subversión de la identidad. Paidós. 196p. México.

Cruz Sierra, S. (2011) Violencia masculina y homicidio masculino en Ciudad Juárez. Ponencia presentada en IV Coloquio Internacional de Estudios sobre Varones y Masculinidades. 19 al 21 de mayo 2011. Montevideo. Uruguay.

De Beauvoir, Simone (1949). Le deuxième sexe. Éditions Gallimard. France.

De Keijzer. B. (2010). iSalud!. La manzana. Revista Internacional de Estudios sobre masculinidades. Vol.5 (8). www.estudiomasculinidades.buap.mx. México.

García Aguilar M., C. (2010). Feminismo transmoderno: Una perspectiva política.Bénemerita Universidad Autónoma de Puebla. México. 459 p.

Labrecque, M. F. (2012). Féminicides et impunité. Le cas de Ciudad Juárez. Écosociété, Canada, 198p.

Lagarde, Marcela (1997). Los cautiverios de las mujeres madresposas, monjas, putas, presas y locas. Pórtico Librerías. 878 p.

Lamas, Marta (1996). El género: la construcción cultural de la diferencia sexual. PUEG/Miguel Angel Porrúa. Colección Las Ciencias Sociales. Estudios de Género. México.

Ovalle, Paola Liliana. (2010). Imágenes abyectas e invisibilidad de las víctimas. Narrativas visuales de la violencia en México. El Cotidiano. No. 164 noviembre-diciembre 2010. México. Pp.103-105

Woolf, Virginia (1929). Une chambre à soi. Bibliothèques 10-18. France.171 p. 
Páginas y blogs consultados:

http://laventana.casa.cult.cu/modules.php?name $=$ News\&file=article\&sid $=4739$

Portal: La ventana

La nudité comme arme politique, reportaje une heure sur terre, Radio Canadá. Vendredi 3 février 2012.

http://www.radio-canada.ca/emissions/une_heure_sur_terre/2011-2012/Reportage. asp?idDoc $=199216$

http://femen.livejournal.com/

http://www.labarbelabarbe.org

http://www.lasbigotonas.com

CIMAC noticia Se desnudan frente a la Cámara de Diputados

Demandan campesinas juicio político a Miguel Angel Yunes Rafael Maya cimac| México, DF, 14 de octubre 2003, http://www.cimacnoticias.com.mx/noticias/03oct/03101403.html

Caracol radio

Mujeres campesinas se suman a protestas y se desnudan en público Agencia EFE | Enero 9 de 2002

http://www.caracol.com.co/noticias/mujeres-campesinas-se-suman-a-protestas-y-sedesnudan-en-publico/20020109/nota/150014.aspx

\section{Algunos Facebook que asocian el cuerpo femenino a una lucha política}

\section{FEMEN}

La Chichi indignada

Comunidad lésbica teta insurgente

La teta feliz

Señoras indignadas

Ciclistas feminista

Marcha de las putas

Marcha de las putas Ecuador

La vagina insurgente

Poner cara de clítoris

Ni putas ni sumisas

El after de "La marcha de las putas."

Cuerpos distintos derechos iguales

La bikina

Colectivo masfaldas

Colectiva transtortillera paila marina

Colectiva maternidad libertaria

Colectivo feminista panteras rosas

Sin cautivas feministas

Palobra No. 13. Agosto de 2013 